\title{
Granuloma venereum
}

\author{
S. B. BHAGWANDEEN AND Y. A. MOTTIAR ${ }^{1}$ \\ From the Department of Pathology, University of Zambia, Lusaka, and the University Teaching Hospital, \\ Lusaka
}

SYNOPSIS Granuloma venereum is endemic in Zambia but there are no previous reports of the disease $\vec{\odot}$ from this geographical area. Six cases of granuloma venereum in African females were discovered obu biopsy specimens. One unusual case with primary cervical involvement simulating carcinoma of the cervix is presented. This case illustrates the difficulties of diagnosis and the ease with which it may be mistaken for malignancy in the absence of histological confirmation.

Granuloma venereum is known by several names, granuloma inguinale (Douglas, 1962; Stewart, 1964) and Donovanosis (Rajam and Rangiah, 1954). The disease is still confused with lymphogranuloma venereum. The latter is caused by a specific virus. Granuloma venereum is caused by Gram-negative bacilli, the Donovania granulomatis (Donovan, 1905; Greenblatt, Dienst, Pund, and Torpin, 1939; Anderson, Demonbreun, and Goodpasture, 1945). There is still doubt, however, whether this organism is solely responsible for granuloma venereum (Stewart; von Haam, 1966).

Both granuloma venereum and lymphogranuloma venereum are classed as venereal diseases although there is some doubt whether sexual contact is essential for transmission of granuloma venereum (Goldberg, 1959; Douglas, 1962). Both diseases are found in association with poor personal hygiene (Hester and Charleston, 1951; Rajam and Rangiah, 1954).

Granuloma venereum is of relatively low contagiousness (Rajam and Rangiah, 1954; Douglas, 1962; von Haam, 1966). Although the primary site of the disease is in the mucocutaneous zone of the genital organs (Rajam and Rangiah, 1954; Hester and Charleston, 1951; Stewart, 1964) extragenital lesions have been described (Lyford, Scott, and Johnson, 1944; Rajam and Rangiah, 1954; Stewart, 1964).

The disease is found predominantly in tropical countries (Rajam and Rangiah, 1954; von Haam, 1966) though it is not unknown in other geographical areas (Cumming, 1920; Rajam and Rangiah, 1954). No cases to my knowledge have been recognized in

'Present address: Groves Memorial Community Hospital, 235 Union Street, E., Fergus, Ontario, Canada.

Received for publication 25 May 1972.
Zambia and the absence of the disease as a differ ${ }_{\overline{0}}^{\vec{N}}$ ential diagnosis in relevant cases on biopsy reques $\overline{\text { }}$ forms indicates that it is not generally recognized that granuloma venereum is endemic in Zambia.

Accurate diagnosis is essential and depend ${ }_{\mathbb{D}}$ finally on demonstrating Donovan bodies either in appropriately stained smears from active lesions or in tissue sections (Hester and Charleston, 1951; Rajam and Rangiah, 1954; Douglas, 1962; Stewart, 1984) The diagnosis may be missed if the disease is rot constantly in the forefront of the mind bothōots clinician and pathologist. The apparent lack awareness of its endemic nature in Zambia and the rather unusual features of this case prompted this report.

\section{Case Summary}

An African woman aged 34 years presented with. irregular vaginal bleeding following an assistes: breech delivery of her last child six weeks earlier. The child was stillborn. She had had four previous uncomplicated pregnancies and her past history was. unremarkable. On pelvic examination the cervix was bulky, hard, irregular, not tender, and mobile. The uterus was of normal size and the parametria were normal. Speculum examination of the cervix reveale hypertrophic papillary erosions which bled easily?. There were no other abnormal physical finding except for a mild anaemia (Hb $10 \mathrm{~g} / 100 \mathrm{ml}$ ). Special investigations added nothing. Endrometrial curret tings and a cervical biopsy were submitted fof
histology and revealed granuloma venereum.

Despite an intensive course of antibiotic therapt there was no change in the cervical lesion after five weeks and an abdominal hysterectomy was per ${ }^{-}$ formed. The patient was free from disease when seen six months later. 


\section{Pathology}

The uterus (hysterectomy specimen) was of approximately normal size except for a bulky cervix. The appearance of the external os was remarkable (Fig. 1) as the entire surface was involved in a fleshy, exuberant type of lesion with focal ulceration and oedematous bullae. The overall impression was that of a very severe cervicitis, but, due to the somewhat hypertrophic appearance, carcinoma of the cervix was a distinct possibility. The bisected uterus also showed the remarkable cervical lesions (Fig. 2). The lesions involved the entire internal os and spread into the lower part of the body of the uterus (Fig. 3). The gross appearance was not unlike that seen in tuberculosis with yellowish, cheese-like caseative areas and unlike the almost white tumour tissue seen in carcinoma. However, on gross appearances, carcinoma of the cervix was a possible diagnosis.

\section{HISTOLOGY}

\section{Initial biopsy}

The predominant feature was that of a severe inflammation and prominence of vascular granulation tissue. The overlying epithelium was markedly thinned out in these areas with ulceration in some areas. The inflammatory infiltrate was rich in poly-

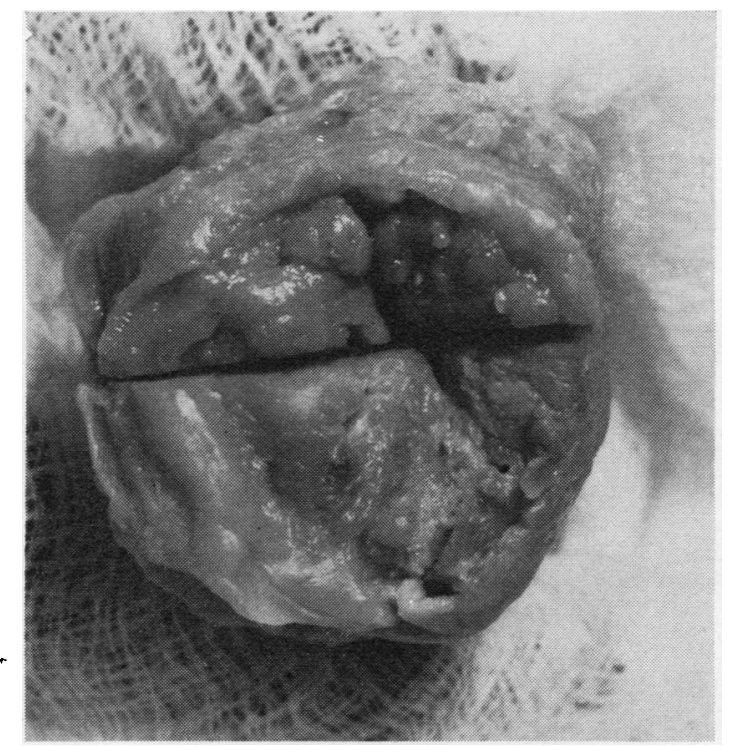

Fig. 1 Cervical lesion: the cervix is totally involved by exuberant oedematous, warty, outgrowths with areas of necrosis and ulceration. Such a lesion can readily be mistaken for malignancy. morphonuclear leucocytes (Fig. 4) with as many plasma cells, lymphocytes, and large foamy macrophages (Fig. 5). Within these macrophages were small inclusion bodies which on the silver stain showed the characteristic features of Donovan bodies (Fig. 6). The silver stain demonstrated in fact that there were large numbers of organisms lying free in the inflammatory exudate (Fig. 7).

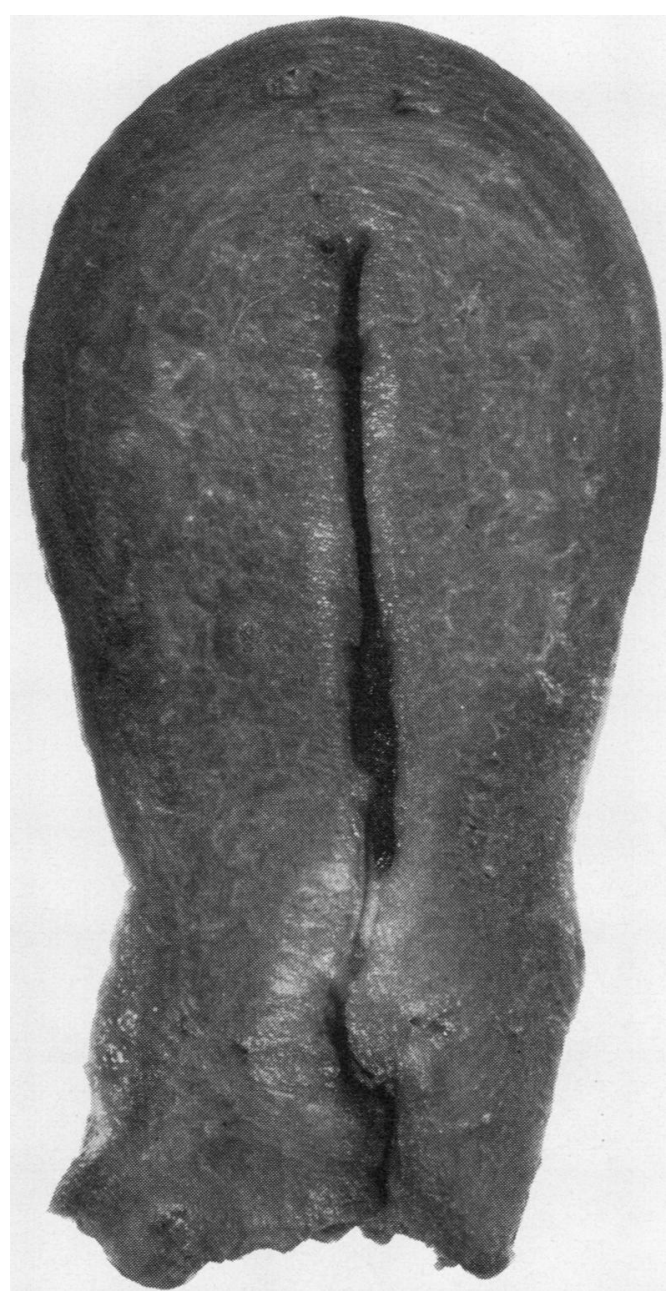

Fig. 2 Uterus: bisected to demonstrate involvement of the internal os. The lesion has spread along the cervical canal and the pale white areas are reminiscent of spreading malignancy. 


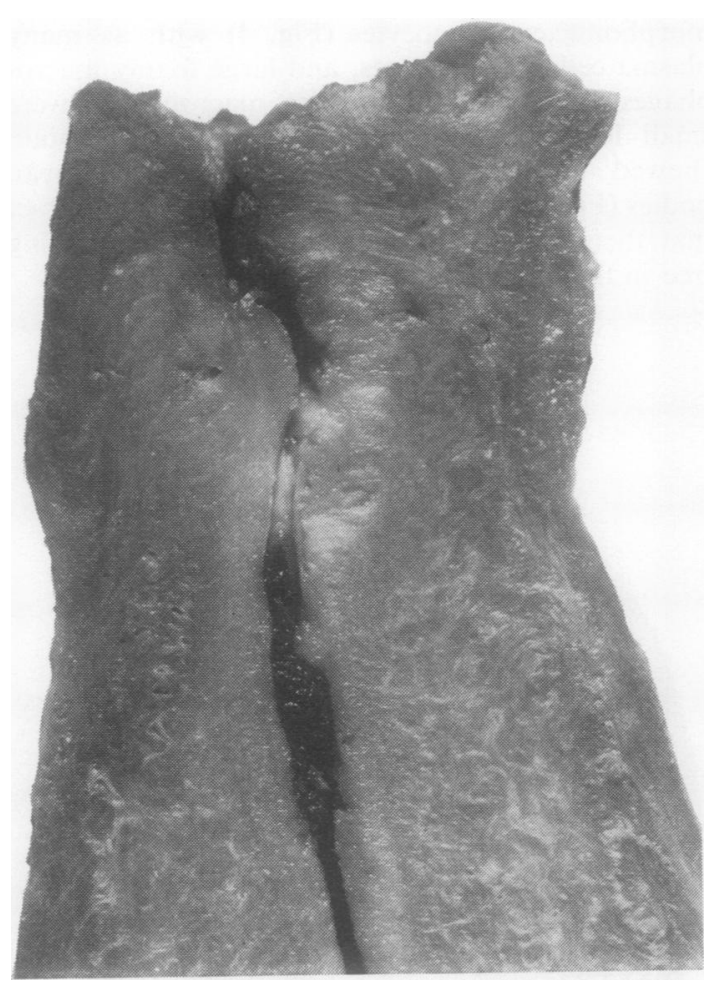

Fig. 3 A closer view of the cervix to illustrate involvement of the cervical canal.

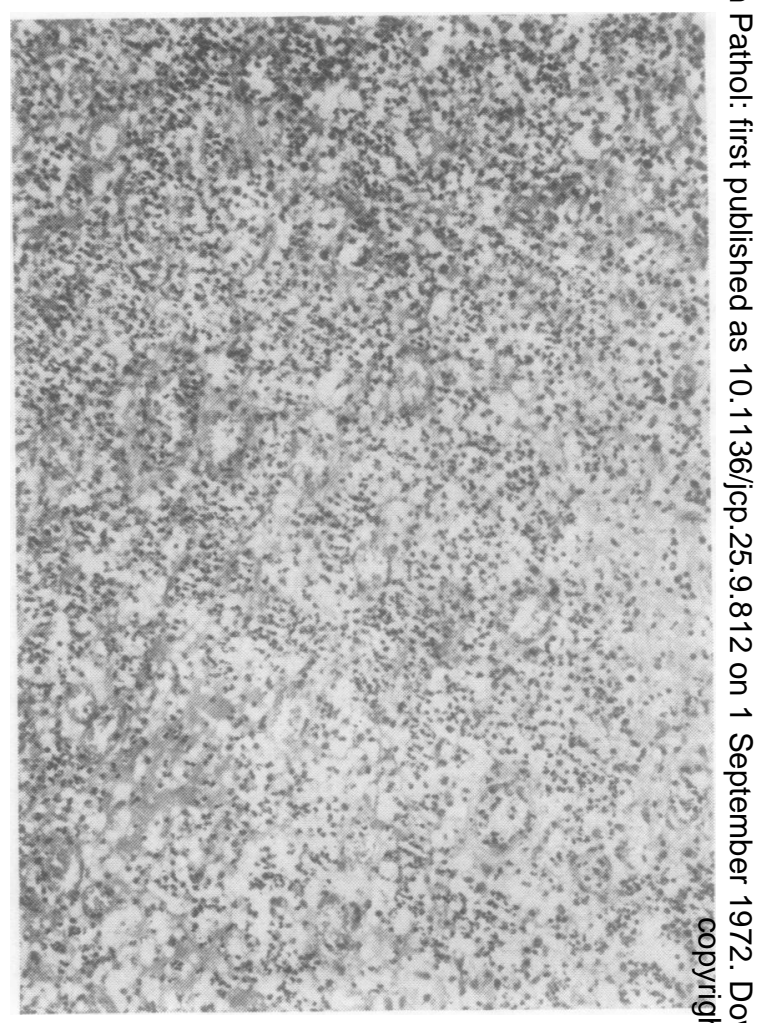

Fig. 4 Histology of original biopsy from cervix showing? exuberant granulation tissues and mixed cellular infiltrate with pale-staining, foamy macrophages. Haematoxylin and eosin $\times 92$.

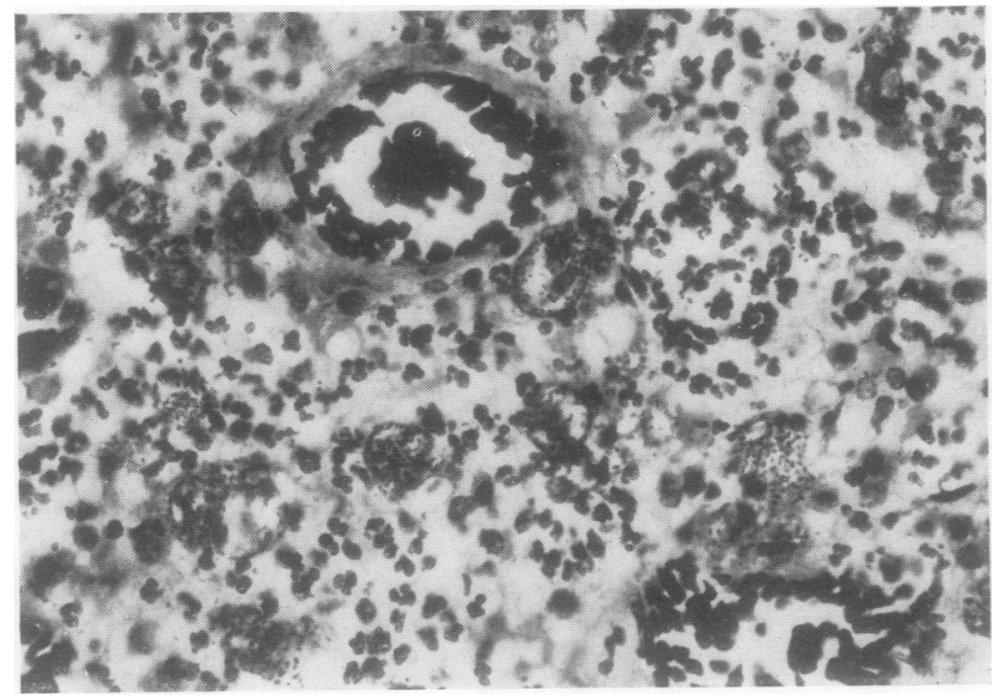

Fig. 5 Higher magnification of granulation tissue stained with silver stain to demonstrate Donovan bodies in the large macrophages. The mixed cellular infiltrate is apparent. Leviditti stain $\times 300$. 


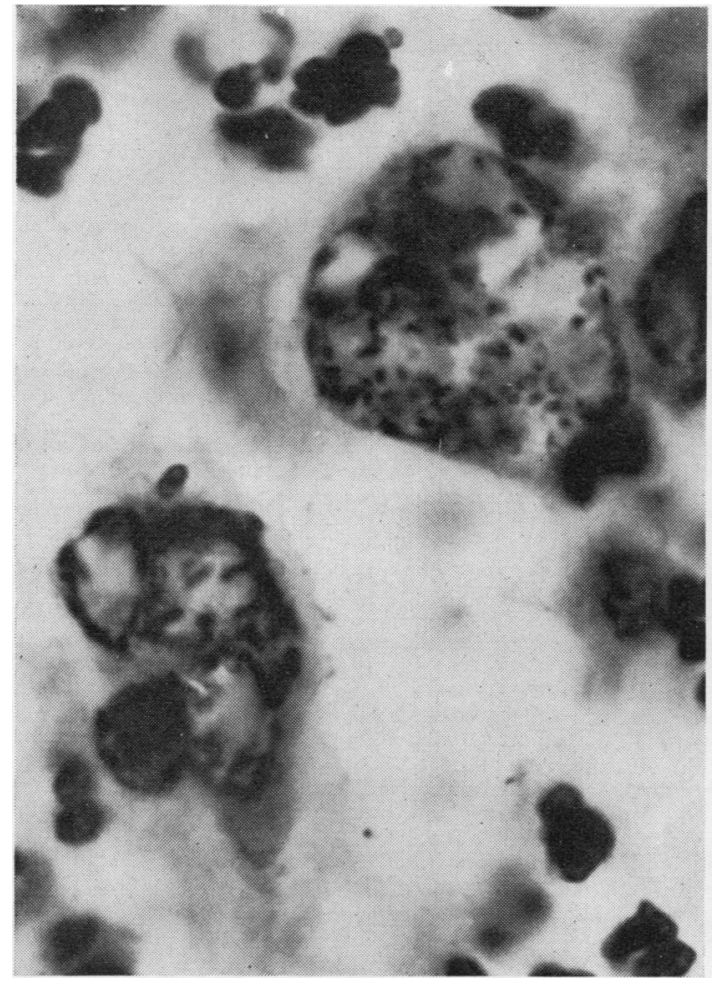

Fig. 6.

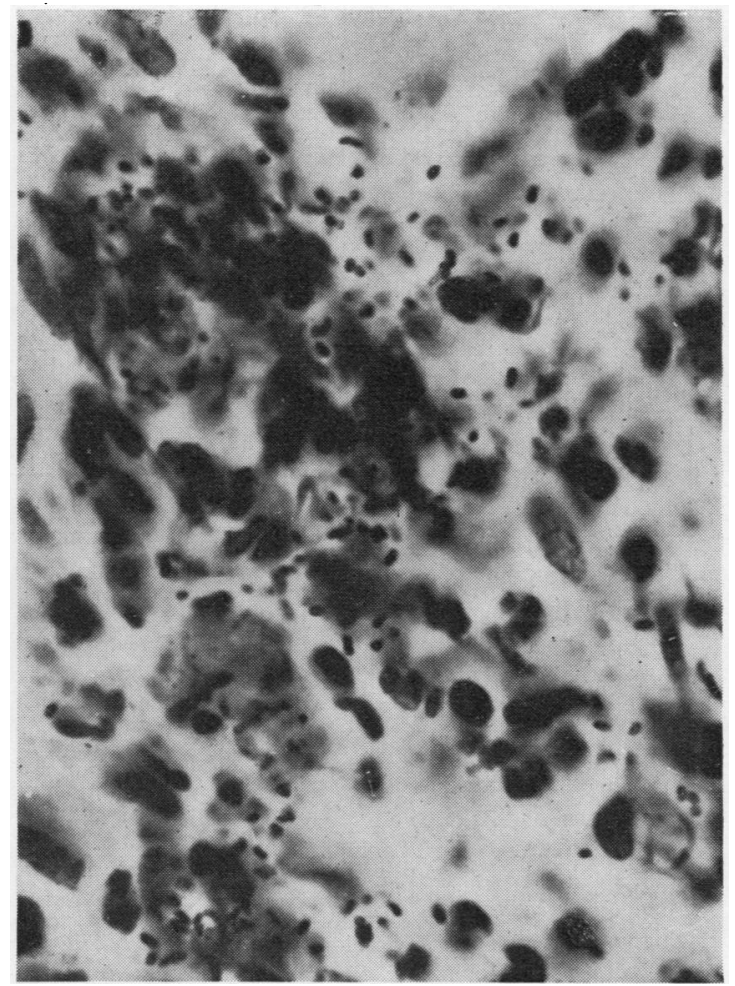

Fig. 7.

Fig. 6 Higher magnification of macrophage containing Donovan bodies. The typical bipolar staining of 'closed safety-pin' appearance is clearly shown. Leviditti $\times 936$.

Fig. 7 Section showing numerous Donovan bodies outside cells in the interstitial tissue. Leviditti $\times 667$.

\section{Hysterectomy specimen}

Multiple sections from the ectocervix, endocervix, and lower part of the body revealed severe chronic inflammatory reaction. Vascular granulation tissue was less profuse. The overlying epithelium was still atrophic. The cellular infiltrate consisted predominantly of plasma cells, some lymphocytes, some macrophage cells, and clusters of large cells with pale, foamy cytoplasm. Within these cells Donovan bodies could again be demonstrated with the silver stain, although these were less numerous than in the original biopsy specimen. There was chronic endometritis in other areas of the body of the uterus, where occasional Donovan bodies could be demonstrated.

\section{Discussion}

During the five years that one of the authors (S.B.B.) has been in Zambia, six cases of granuloma venereum were discovered in biopsy specimens. All the cases were in women. Two were cervical biopsies while the other four were biopsies of ulcers on the labia and vagina. In none of the cases was the diagnosis suspected clinically. In each case diagnosis was made by identifying the typical Donovan bodies in tissue sections. Other authors have commented on the difficulty of demonstrating these organisms in tissue sections (Stewart, 1964).

The patient reported here had, after diagnosis on the original biopsy, a full course of streptomycin therapy. However, Donovan bodies were readily demonstrable in the tissue sections of the cervical lesions approximately six months after therapy. This contrasts with the view expressed by Hester and Charleston (1951) that the organisms disappear shortly after specific therapy has been instituted.

The presentation of the disease depends on the stage at which the patient seeks medical advice. The classical presentation is that of an ulcer on the externala genitalia which gradually spreads to involve adjacent structures and organs. (Hester and Charleston, 1951; Rajam and Rangiah, 1954; 
Douglas, 1962; Stewart, 1964). Involvement of the cervix is regarded as a late manifestation of the disease (Rajam and Rangiah, 1954; Douglas, 1962). Primary involvement of the cervix is uncommon (Rajam and Rangiah, 1954).

In this case, although involvement of the cervix was extensive, there were no stigmata of primary external genital involvement such as disfiguring cicatrization or elephantiasis (Hester and Charleston, 1951; Rajam and Rangiah, 1954; Stewart, 1964). The lack of these stigmata favours a primary lesion of the cervix.

From this brief report it is apparent that granuloma venereum is endemic in Zambia. However, due to the almost epidemic proportions of carcinoma of the cervix in Zambia (Hassim, 1968) all suspicious lesions of the cervix are regarded as malignant until proved otherwise.

This case also emphasizes the point made by all workers that granuloma venereum is a laboratory diagnosis. In Zambia the pathologist should be aware of the entity of granuloma venereum as the diagnosis may be easily missed. The histological features are not diagnostic and diligent search for Donovan bodies may be necessary for a correct diagnosis.

I wish to thank Mr M. A. Ansary for assistance with the illustrations and Dr M. N. Nalumango, Permanent Secretary for Health, for permission to publish.

References

Anderson, K., DeMonbreun, W. A., and Goodpasture, E. W. (1945). An etiologic consideration of Donovaniagranulomat is cultivated from granuloma inguinale ( 3 cases) in embryonic yolk. J. exp. Med., 81, 25-40.

Cumming, H. L. (1920). Ulcerating granuloma of the pudenda cured by intramuscular injections of antimony tartrate. Brit. med. J 2, 775-777.

Donovan, C. (1905). Medical cases from Madras General Hospital. Indian med. Gaz., 40, 411-414. Cited by Rajam and Rangiah $C$ (1954).

Douglas, C. P. (1962). Lymphogranuloma venereum and granuloma inguinale of the vulva. J. Obstet Gynaec. Brit. Cwlth, 69, 871880 .

Goldberg, J. (1959). Studies on granuloma inguinale: IV. Growth requirements of Donovania granulomatis and its relationship $\widehat{\Omega}$ to the natural habitat of the organism. Brit. J. vener. Dis., 35, 266-268.

Greenblatt, R. B., Dienst, R. B., Pund, E. R., and Torpin, R. (1939). Experimental and clinical granuloma inguinale. J. Amer. med. Ass., 113, $1109-1116$.

Haam, E. von (1966). Granuloma venereum. In Pathology, 5th ed., edited by W. A. D. Anderson, Vol. 1, pp. 247-248. Mosby, St. Louis.

Hassim, A. (1968). Another preventable disease-carcinoma of the cervix. Zambia med. J., 2, 1-2.

Hester, L. L., Jr., and Charleston, S. C. (1951). Granuloma venereum of the cervix and vulva. Amer. J. Obstet. Gynec., 62, 312-320.

Lyford, J. III, Scott, R. B., and Johnson, R. W. Jr. (1944). Polyarticular arthritis and osteomyelitis due to granuloma inguinale. Amer. J. Syph., 28, 588-610.

Rajam, R. V., and Rangiah, P. H. (1954). Donovanosis (granuloma inguinale, gra nuloma venereum). Wld. Hlth. Org. Monogr. Ser No. 24.

Stewart, D. B. (1964). The gynaecological lesions of lymphogranto $N$ loma venereum and gra nuloma inguinale. Med. Clin. N. Amers 48, 773-78ú. 